\title{
Effect of Premicturitional Bladder Volume on the Accuracy of Sonographic Assessment of Post Void Residual Urine Volume Measurement by Transabdominal Ultrasonography
}

\author{
Roshani Pathak, Sunil Pradhan, Abhushan Tuladhar, Amit Shrestha and Riwaz Acharya
}

Department of Radiology, Nepal Medical College and Teaching Hospital, Jorpati, Kathmandu. Nepal

\begin{abstract}
Introduction: The Post Void Residual Urine volume (PVRU) is frequently significant in patients with bladder outflow obstruction; especially in patients with enlarged prostate and prostatism. The PVRU forms an important part of radiological investigation. Accurate measurement of the residual urine volume changes observed serially over a period of time may indicate clinical progress. The purpose of this study was to evaluate the effect of pre-void bladder volume on PVRU measurements.

Methods: A prospective study was conducted to determine the accuracy of PVRU measurement in patient presenting with lower urinary tract symptoms (LUTS). 50 patients with LUTS were assessed ultrasonographically for pre void and post void bladder volumes during the study period of March 2017 till August 2017. PVRU measurements done in patients with bladder filling sensation at moderate to full capacity resulted in high estimations of PVRU which was quite significant in this study.

Results: There was significant difference in the estimated PVRU between patients having high initial premicturitional volume $(546 \pm 144 \mathrm{ml})$ than those with lower or moderate filling volume $(261 \pm 58 \mathrm{ml})$ with mean of $173 \mathrm{ml}$ and $35 \mathrm{ml}$ respectively. The difference in estimated PVRU was highly significant with $p$ value of $<0.0001$.

Conclusions: Measurement of pre void urinary bladder volume with an uncomfortably full bladder results in high post micturitional (PMRU) values even in most patients without lower urinary tract symptomswhich may be false-positive. We advise that initial or pre-void urine volume be measured when the patient has initial or moderate feeling of bladder fullness.
\end{abstract}

Keywords: PVRU; LUTS; Ultrasonography; Urine volume estimation

Correspondence: Roshani Pathak, Department of Radiology, Nepal Medical College and Teaching Hospital, Attarkhel, Jorpati, Kathmandu, Nepal; E-mail: drroshanipathak@yahoo.co.in

DOI: $10.3126 / \mathrm{mjsbh} . v 18 \mathrm{i} 1.19937$

Submitted on: 2018-05-20

Accepted on: 2018-12-02 


\section{INTRODUCTION}

Lower Urinary Tract Symptoms (LUTS) refer to a group of clinical symptoms involving the bladder, urinary sphincter, urethra, and, in men, the prostate, affecting approximately $40 \%$ of older men. ${ }^{1}$ LUTS is a preferred and newer term for prostatism, and it is more common for the term to be applied to men. ${ }^{2}$ However, obstructive disorders of the lower urinary tract may also be caused by other diseases, such as bladder neck contractures, urethral valves, or external sphincter dyssynergia and can affect women as well. However, for the majority of cases in the male population, the etiology is benign prostatic hyperplasia. ${ }^{3}$ Post void residual urine was recommended by the Fifth International Consultation for the diagnostic work-up of LUTS especially for patient follow up secondary to benign prostatic hyperplasia. ${ }^{4}$ The PVRU is defined as the volume of urine remaining in the bladder immediately after the completion of micturition. ${ }^{5}$ It can be measured by transurethral catheterisation, by radiographic studies, or by ultrasound examination. ${ }^{6}$ Increased PVRU is a common finding in patients presenting with LUTS in older age groups and ultrasound is the primary modality of investigations in such patients.

Accurate assessment of this volume forms an important first line investigation, and contributes significantly towards diagnosing voiding dysfunction and in the diagnosis and management of these patients. ${ }^{7}$ There is significant correlation of PVRU with LUTS especially prostatic volume and such patients are more likely to develop acute urinary retention. The advantages of ultrasound in assessment of PVRU as compared to urethral catheterisation or urodynamic studies is that it is non invasive and is not linked to urethral trauma or increased incidence of urinary tract infection. 8,9 Transabdominal ultrasound can be a reliable method for estimation of PVRU.9-13 Urethral catheterisation of bladder may be more accurate but not always practicable. ${ }^{11}$

Usually, the patients whose PVRU is to be measured are instructed to drink large amount of fluids before the examination. However, large amount of fluid intake may stress and temporarily decompensate the urinary bladder leading to unreliable PVRU measurements especially in patients with LUTS. ${ }^{7}$ Larger PVRU often indicates lower urinary tract dysfunction and may predispose to unsatisfactory treatment results if invasive bladder outlet obstruction is undertaken. ${ }^{14}$ The aim of this study was to find out the effect of premicturitional bladder volume on the accuracy of sonographic assessment of PVRU in Nepalese patients with LUTS.

\section{METHODS}

The study was conducted at one of the Teaching Institutes of Kathmandu, Nepal from March to August 2017. Male patients above the age of 40 years presenting with LUTS to the Department of Radiology for ultrasound evaluation were included in the study. The approval of the hospital ethic committee was obtained for this prospective study.

Patients having Foley's catheter in place either following urinary retention or neurological condition were excluded from the study. Patients with history of previous abdominal operations or urolithiasis were also excluded from the study. In this prospective study the null hypothesis is that initial or pre void urine volume in bladder has no effect on post-micturition residual urine as calculated by trans-abdominal ultrasound. The level of statistical significance was set at 0.05 with 80 percent power. Statistical tables and resources at biomath info was used to analyse data after initial calculation and tabulation in Microsoft Office Excel. 
A total of 50 patients were included in the study. The patients were divided into two groups assigned in an alternate manner. The first group included 25 patients with pre void estimated urine volume of up to $250 \mathrm{ml}$ or the patient had initial feeling of having fullness. The second group included another 25 patients with pre void urine volume of more than $250 \mathrm{ml}$ or completely full bladder. After the bladder was filled up by the intake of a significant amount of water, the urinary bladder was scanned using Toshiba machine $\mathrm{B}$ mode $5 \mathrm{MHz}$ probe transducer and the mean of three being taken as the final value. A thorough urinary tract ultrasound examination was carried out by a radiologist including the status of kidneys, ureter, bladder and prostate gland. The patients then emptied their bladder and the PVRU was noted. The pre void volume was recorded in full bladder. Patients were then instructed to pass urine and post void urine was recorded immediately.

The values obtained were recorded on Excel sheet and further statistical analysis was done. Student's t- test was used to compare the two groups and a $p$ value of $<0.05$ considered significant.

\section{RESULTS}

Mean pre void urine volume in the first group (Table 1) was $261.6 \mathrm{ml}$ (range of 154-335 ml), while mean pre void urine volume in the second group (Table 1) was $546.04 \mathrm{ml}$ (range 357-920 ml). Mean PVRU in the first group was $35.71 \mathrm{ml} \pm 19.55$ (range of 10 to $80 \mathrm{ml}$ ). Mean PVRU in the second group was $173.91 \pm 84.86 \mathrm{ml}$ (range of 20.8 to 340 $\mathrm{ml})$. The mean age of group one is 54.5 and the group two is 53.8 years.

Statistical analysis and two tailed unpaired $t$-test of the collected data yields a p-value of less than 0.0001 hence the null hypothesis is rejected. By conventional criteria, this difference is considered to be extremely statistically significant with significant difference in PVRU depending upon pre-void urine amount in the urinary bladder at the time of initial ultrasound.

The relation between initial and post void residual urine in the two groups is illustrated in Chart 1 through line diagram.

\section{DISCUSSION}

Post void residual urine volume measurement is currently recommended for the initial evaluation and treatment follow-up of patients who present with lower urinary tract symptoms. ${ }^{4,7}$ The majority of patients who are subjected to PVRU estimation are advised to increase their fluid intake and to urinate when the bladder is full or when they experience moderate to severe urgency to void. ${ }^{12,14,15}$ Many urologists suggest that high post void values are an indication for surgery.16,17 Due to this reason accurate measurement of PVRU is vital for the diagnosis and managements of patients with LUTS, especially secondary to enlarged prostrate.

Table 1. Characteristics of patients: Group 1 (Mild filling) and Group 2 (Full bladder) at the time of pre micturition urinary volume.

\begin{tabular}{|c|c|c|c|c|c|c|}
\hline $\begin{array}{l}\text { Number of } \\
\text { patients in } \\
\text { each Group } \\
=\mathbf{2 5}\end{array}$ & $\begin{array}{l}\text { Mean age } \\
\text { Group } 1\end{array}$ & $\begin{array}{l}\text { Mean Pre- } \\
\text { void } \\
\text { Bladder } \\
\text { Volume } \\
\text { Group 1 } \\
\text { (in ml) }\end{array}$ & $\begin{array}{l}\text { Mean Post } \\
\text { Void } \\
\text { Residual } \\
\text { Urine } \\
\text { Volume } \\
\text { Group 1 } \\
\text { (in ml) }\end{array}$ & $\begin{array}{l}\text { Mean Age } \\
\text { Group } 2\end{array}$ & $\begin{array}{l}\text { Mean Pre } \\
\text { Void } \\
\text { Bladder } \\
\text { Volume } \\
\text { Group } 2 \\
\text { (in ml) }\end{array}$ & $\begin{array}{l}\text { Mean Post } \\
\text { Void } \\
\text { Residual } \\
\text { Urine } \\
\text { Volume } \\
\text { Group 2 } \\
\text { (in ml) }\end{array}$ \\
\hline Mean & 54.52 & 261.65 & 35.71 & 53.84 & 546.04 & 173.91 \\
\hline $\begin{array}{l}\text { Standard } \\
\text { deviation }\end{array}$ & 4.75 & \pm 58.02 & 19.55 & 5.89 & \pm 144.02 & \pm 84.86 \\
\hline
\end{tabular}




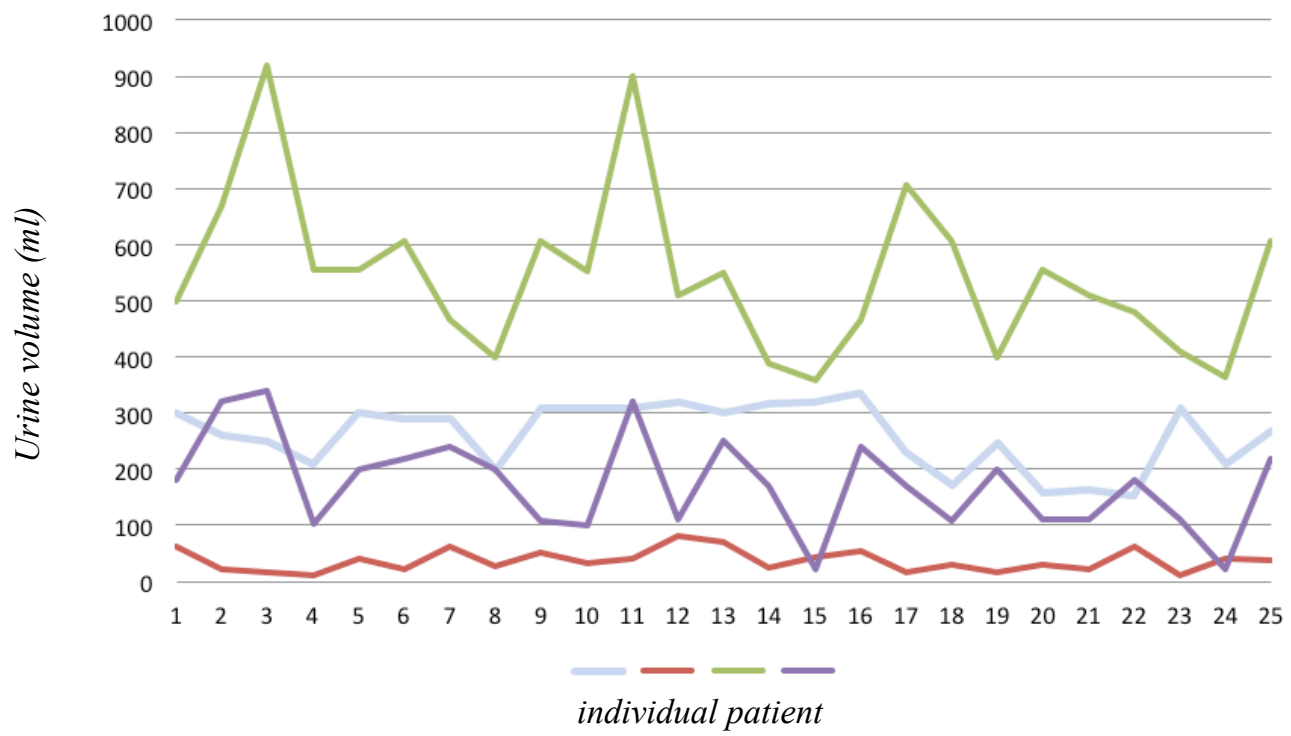

Series 1 (in blue): Pre Void Bladder Urinary Volume in Group 1

Series 2 (in brown): Post Void Residual Urine Volume in Group 1

Series 3 (in green): Pre Void Bladder Urinary Volume in Group 2

Series 4 (in deep blue): Post Void Residual Urine Volume in Group 2

$\mathrm{X}$ axis is individual patient and $\mathrm{Y}$ axis is urine volume in $\mathrm{ml}$.

Fig 1. Chart showing relation between pre and post void urine in Group 1(mild filling) and Group 2 (full bladder)

The patients with low post void residual urine volumes are managed conservatively and are unlikely to have sudden urinary retention. ${ }^{18,22}$

Urethral catheterisation has been considered to be the gold standard for PVRU measurement ${ }^{10,11}$, but it may lead to urethral trauma and urinary tract infection. Urodynamic studies are more informative but do alter the result as they are present in bladder cavity. Although some studies suggest poor correlation between the bladder volumes predicted by ultrasonography and those obtained by urethral catheterisation, ultrasonography is a reliable, inexpensive, noninvasive and simple method. ${ }^{9-13}$

In clinical practice patients waiting for PVRU measurement by ultrasound are asked to drink large amounts of fluids to distend their bladder before ultrasound. Many a times, these patients have to wait longer in a busy Radiology Department awaiting their turn, resulting on overfilling of their bladders. Consequently they are unable to empty their bladders fully after first assessment, resulting in observation of a large PVRU. ${ }^{18}$ Ozden et al. have reported significant amount of residual urine volume even in young healthy subjects who had large urine volume at initial examination. High pre void urine volumes in these subjects cause high false positive PVRU values as has been observed in our study. ${ }^{19}$

In a study by Alivizatos et al., the authors looked into the consistency of PVRU measurements after filling the bladder to maximum capacity, with high fluid load and the patients emptied their bladders at the first desire to void. The study showed that the mean PVRU value was $195 \mathrm{ml}$, when the patients voided after a full bladder, compared to a mean PVRU value of only $41 \mathrm{ml}$ when they voided later than the first desire to void. These figures and recommendations are quite similar to our 
conclusions. The authors recommend that PVRU measurements should be performed at the first desire to void because the patients with over distended bladders may be unable to fully empty their bladders resulting in unreliable PVRU measurements. ${ }^{7}$

Our study showed similar findings with high mean PVRU of $215 \mathrm{ml}$ in patient with high pre void volume compared to $19 \mathrm{ml}$ in patients with low pre void volume. Blankers et al. find that moderate to severe LUTS symptoms was independent of prostate volume, but dependent on age, a reduced flow rate, PVRU, and functional bladder capacity on multivariate analysis and recommended that PVRU should be measured when the bladder is filled to its maximum capacity. ${ }^{20}$ The present study did not account for IPSS scores and flow rate but can be taken under consideration in future.

Milleman et al. states that PVRU represents the summation effect of the functions of the bladder and urethral sphincter mechanism. Over distended bladders may temporarily result in acutely stressed and decompensated detrusor muscles leading to incomplete emptying resulting in high PVRU values. $^{21}$

Eric Ozden et al. performed similar study on healthy young men and concluded that a minimum pre void bladder volume of $200 \mathrm{ml}$ and no greater than $540 \mathrm{ml}$ leads to optimum evaluation of PVRU. The pre void bladder volumes above $540 \mathrm{ml}$ led to false high PVRU values. This problem is compounded in patients with LUTS leading to false high estimations of PVRU. This results in errors in diagnosis and further management problems for both the patient and the treating physician. ${ }^{19}$

\section{CONCLUSIONS}

We conclude that patients with LUTS who have an uncomfortably full bladder before ultrasonography are likely to have false high estimations of PVRU values. It is recommended that ultrasonography in these patients be performed with moderately full bladders at the time of first desire to void.

To cite this article: Pathak R. Effect of premicturitional bladder volume on the accuracy of sonographic assessment of post void residual urine volume measurement by transabdominal ultrasonography. MJSBH. 2019;18(1):30-6.

Conflict of Interest: None declared

\section{REFERENCES}

1. Roehrborn CG, McConnell JD. Etiology, pathophysiology, epidemiology, and natural history of benign prostatic hyperplasia. In: Campbell's urology. 8th ed. Philadelphia: Saunders. 2002;1309-11.

2. Abrams T. New words for old: lower urinary tract symptoms for "prostatism". BMJ. 1994;308:929-30. DOI: https://doi.org/10.1136/bmj.308.6934.929 PMid:8173393 PMCid:PMC2539789

3. Tokgoz O, okgoz HT, Unal I, Delibas U, Yildiz S, Voyvoda N et al. Diagnostic values of detrusor wall thickness, postvoid residual urine, and prostate volume to evaluate lower urinary tract symptoms in men. Diagn Interv Radiol. 2012;18:277-81.

PMid:22183877

4. de la Rosette JJ, Alivizatos G, Madersbacher S, Perachino M, Thomas D, Desgrandchamps F, et al. EAU Guidelines on benign prostatic hyperplasia (BPH). Eur Urol. 2001;40(3):256-63..

DOI: https://doi.org/10.1159/000049784 PMid:11684840 
5. Adelwahab HA, Abdalla HM, Sherief MH, Ibrahim MB, Shamaa MA. The reliability and reproducibility of ultrasonography for measuring the residual urine volume in men with lower urinary tract symptoms. Arab J Urol. 2014;12,285-9.

DOI: https://doi.org/10.1016/j.aju.2014.10.002 PMid:26019963 PMCid:PMC4435519

6. Al-shaikh G, Larochelle A, Campbell CE, Schachter J, Baker K, Pascali. Accuracy of bladder scanning in the assessment of postvoid residual volume. J Obstet Gynaecol Can. 2009;31(6):526-32.

DOI: https://doi.org/10.1016/S1701-2163(16)34215-3

7. Alivizatos G, Skolarikos A, Albanis S, Ferakis N, Mitropoulos D. Unreliable residual volume measurement after increased water load diuresis. Int J Urol. 2004;11:1078-81.

DOI: https://doi.org/10.1111/j.1442-2042.2004.00951.x PMid:15663678

8. May M, Brookman-Amissah S, Hoschke B, Gilfrich C, Braun KP, Kendel F. Post-void residual urine as a predictor of urinary tract infection -is there a cutoff value in asymptomatic men? The Journal of urology. 2009;181(6):2540-4.

https://doi.org/10.1016/j.juro.2009.01.103 PMid:19375097

9. Amole AO, Kuranga SA, Oyejola BA. Sonographic assessment of postvoid residual urine volumes in patients with benign prostatic hyperplasia. J Natl Med Assoc. 2004;96:234-9.

PMid:14977284

10. Griffiths DJ, Harrison G, Moore K, McCracken P. Variability of post void residual urine volume in the elderly. Urol Res. 1996;24:23-6.

DOI: https://doi.org/10.1007/BF00296729 PMid:8966837

11. Simfroosh N, Dadkhan F, Hosseini SY, Asgari MA, Nasseri A, Safarinejad MR. Accuracy of residual urine measurement in men: comparison between real -time ultrasonography and catheterisation. J Urol. 1997;158:59-61.

DOI: https://doi.org/10.1097/00005392-199707000-00016ＰMid:9186323

12. Ireton RC, Krieger JN, Cardenas DD, Williams-Burden B, Kelly E, Souci T, et al. Bladder volume determination using a dedicated, portable ultrasound scanner. Journal Urol. 1990 May;143(5):909-11.

DOI: https://doi.org/10.1016/S0022-5347(17)40133-9

13. Coombes GM, Millard RJ. The accuracy of portable ultrasound scanning in the measurement of residual urine volume. J Urol. 1994;152:2083-5.

DOI: https://doi.org/10.1016/S0022-5347(17)32314-5

14. Dunsmuir WD, Feneley M, Corry DA, Bryan J, Kirby RS. The day-to-day variation (test-retest reliability) of residual urine measurement. BJU. 1996;77:192-3.

DOI: https://doi.org/10.1046/j.1464-410X.1996.08524.x PMid:8800883

15. Kolman C, Girman CJ, Jacobsen SJ, Lieber MM. Distribution of post void residual urine Volume in randomly selected men. J. Urol. 1999;161:122-7.

DOI: https://doi.org/10.1097/00005392-199901000-00040

16. Hansen MV, Wold T. A survey concerning the attitudes of urologists toward prostatism patients. Scand. J. Urol. Nephrol. 1994;28:257-64.

PMid:7529432

17. Wasson JH, Reda DJ, Buskewitz RC, Elinson J, Keller A, Henderson WG. A comparison of transurethral surgery with watchful waiting for moderate symptom of benign prostatic hyperplasia. N. Engl. J. Med. 1995;332:75-9.

DOI: https://doi.org/10.1056/NEJM199501123320202 PMid:7527493

18. Mahamood T, Farooq K. Sonographic assessment of post void residual volume in patients with lower urinary tract symptoms. PJMHS. 2010 Jul;4(3):239-41. 
19. Ozden E, Turgut AT, Gogus C, Kosar U, Baltaci S. Effect of Premicturitional Bladder Volume on the Accuracy of Post void Residual Urine volume Measurement by Transabdominal Ultrasonography. J Ultrasound med. 2006;25:831-4.

DOI: https://doi.org/10.7863/jum.2006.25.7.831 PMid:16798893

20. Blanker MH, Groeneveld FP, Bohnen AM, Bernsen RM, Prins A, Thomas S, et al. Voided volumes: normal values and relation to lower urinary tract symptoms in elderly men, a community-based study. Urology. 2001 Jun;57(6):1093-8.

DOI: https://doi.org/10.1016/S0090-4295(01)00988-8

21. Milleman M, Langenstroer P, Gurlanick ML. Post void residual urine volume in women with overactive bladder symptoms. J Urol. 2004;172:1911-4.

DOI: https://doi.org/10.1097/01.ju.0000140502.34334.75 PMid:15540753

22. Asimakopoulos AD, De Nunzio C, Kocjancic E, Tubaro A, Rosier PF, Finazzi-Agrò E. Measurement of post-void residual urine. Neurourology and urodynamics. 2016 Jan;35(1):55-7.

DOI:10.1002/nau.22671 PMID:25251215 